\section{Hard times}

\section{for high tech}

Computer and

telecoms firms are

losing money and

laying off staff - yet

say that $R \& D$ remains

a priority. Can their

scientists really remain

immune to the

economic downturn?

Declan Butler and Jim

Giles investigate.

$\mathrm{J}$ ust two years ago, high-tech computing and telecommunications companies were on the crest of an economic wave. Mobile phones had hit the mass market and sales of computing equipment were buoyant, driven in large part by rapidly increasing Internet use. Investors rushed to embrace technology and dotcoms, and the Nasdaq high-tech stock-market soared to unprecedented levels.

In 2001, the bubble has burst in spectacular fashion. Nasdaq now lies in the doldrums, and high-tech firms' optimistic projections look seriously misplaced. Demand for mobile phones is down, and over-investment in the infrastructure of the Internet - optical-fibre networks and the equipment needed to run them - has left telecoms companies with a glut of unused technology. Computing sales are stagnant, and the chip market has become much more competitive.

Many analysts believe the global economy is on the brink of a full-blown recession. Factor in the economic fallout from the terrorist outrages in New York and Washington, and the outlook appears extremely gloomy. The worst-affected high-tech companies employ thousands of researchers. So what can the scientist at the bench expect to happen to his or her research budget?

In those companies that have made the worst misjudgements, researchers are deeply worried about the future. The British electronics company Marconi has a proud research tradition, tracing its roots back to the Wireless Telegraph and Signal Company, founded in 1897 by radio communications pioneer Guglielmo Marconi. But its decision to concentrate on telecoms has proved

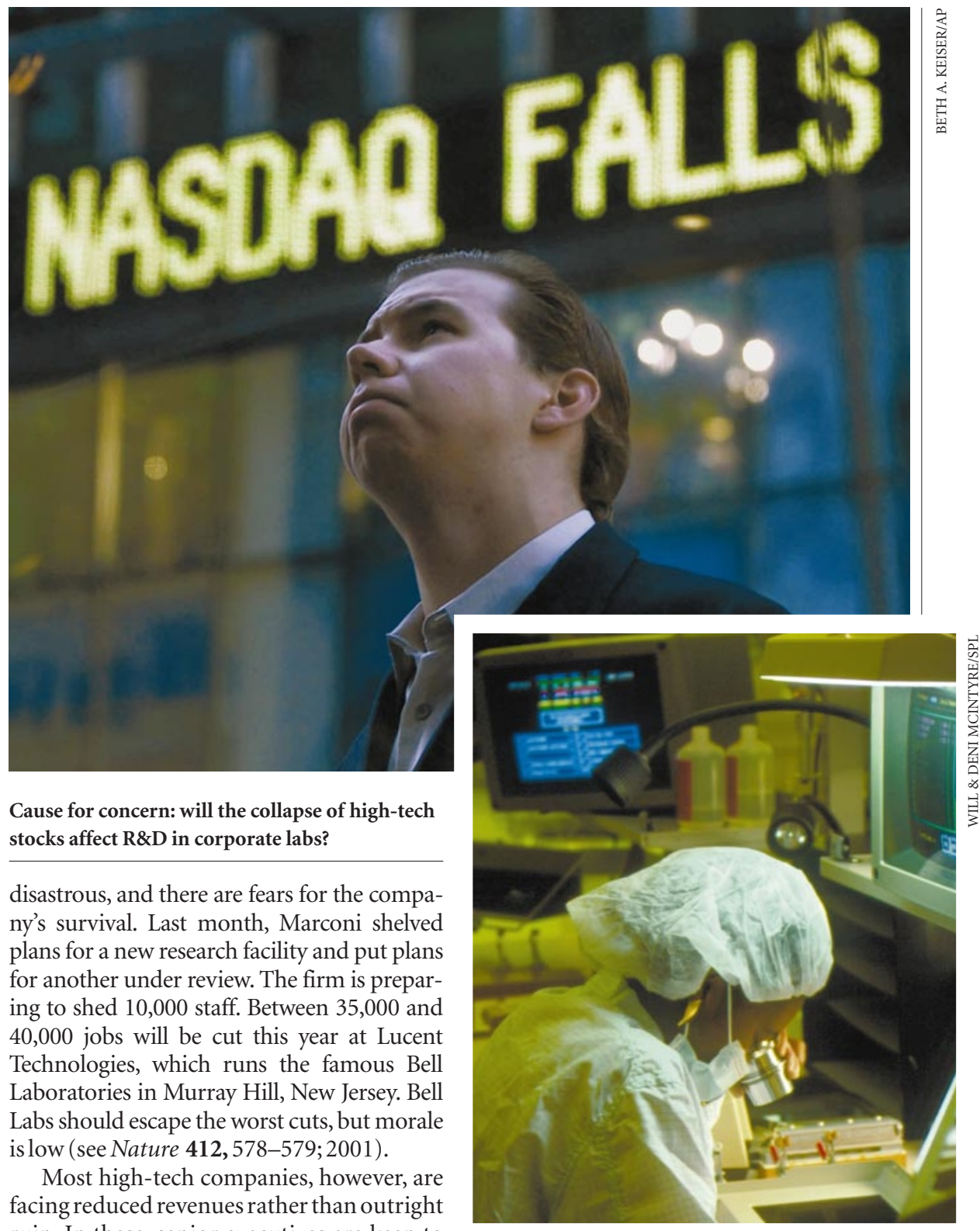

ruin. In these, senior executives are keen to protect their R\&D spending. Belts are being tightened, but research expenditure will not be the first to be cut. Some companies are even planning to increase investment in $\mathrm{R} \& \mathrm{D}$, as the best way to ensure their continued competitiveness. Demand for the firms' current products may be static, but they know that they must be ready with the next generation when the economic gloom lifts.

\section{Seizing the opportunity}

"We have learnt that this is precisely the time that you want to be there with new products," says David Tennenhouse, director of research with the chip manufacturer Intel. He argues that a recession actually provides one of the best opportunities to pull ahead of the competition. With demand for the Pentium chips that sit inside the majority of personal computers having levelled off, Intel is now upping its $\mathrm{R} \& \mathrm{D}$ spending in order to focus on processors for mobile and wearable devices. On the software side, Bill Gates has been similarly bullish about $\mathrm{R} \& \mathrm{D}$, saying that Microsoft's US\$3.8-billion investment last year will increase to $\$ 5$ billion this year.

This commitment to $\mathrm{R} \& \mathrm{D}$ is echoed at other leading high-tech firms. "The percentage of revenues we spend on $R \& D$ is going up," says Dennis Roberson, chief technology officer of Motorola, a leading player in mobile telecommunications and microchips. "I say this with a wry smile," he adds, "because revenues are actually falling faster than we are putting the percentage up. But R\&D will not decrease by very much." do not necessarily mean that researchers will be immune to the problems of the high-tech sector. Some analysts say that firms' commitment may waver if the downturn becomes a prolonged recession. Others suggest that the safety of research is relative and depends on the size and type of firm. Commercial R\&D labs may also see more of their basic research farmed out to universities - accelerating a
But these statements of support for $\mathrm{R} \& \mathrm{D}$ 
trend that has emerged in recent years.

Even if the official R\&D spending figures do remain stable, they may hide the full picture. $R \& D$ is notoriously difficult to define and the figures can be subject to creative accounting. Michael Blogg, an information-technology analyst at the London branch of investment bankers ING Barings, says that companies need to appear to be maintaining their R\&D spending in order to satisfy investors. During previous recessions in the 1980s and 1990s, some companies reclassified other technical staff as $R \& D$ workers to hide cuts, experts say.

Threats to R\&D are not spread out evenly across all companies. "Typically in a downturn, small firms are hurt more than large firms," says Sam Kortum, an economist at Boston University who specializes in technology and innovation. Companies with a wide range of products, such as IBM, can shield their R\&D efforts from reduced revenues in one area. But smaller firms specializing in the worst-hit areas, such as telecoms networks and the electronics needed to run them, have nowhere to hide. Analysts warn that small companies trying to bring their first product to the market may go under.

Such companies survive on venture capital, and David Marino-Nachison, a writer for investors' website The Motley Fool, says that the current climate may force fund managers to shift their focus. "They'll be looking for companies that are further along the development cycle, or stand a chance of making a profit sooner," he says.

But small companies should fare better than in previous recessions, as the venturecapital industry now has more funding and better expertise. "The problem in the 1980s and 1990s was that the institutions were only just beginning to emerge," says Margaret Sharp, formerly a science-policy researcher and now a Liberal Democrat peer in Britain's House of Lords.

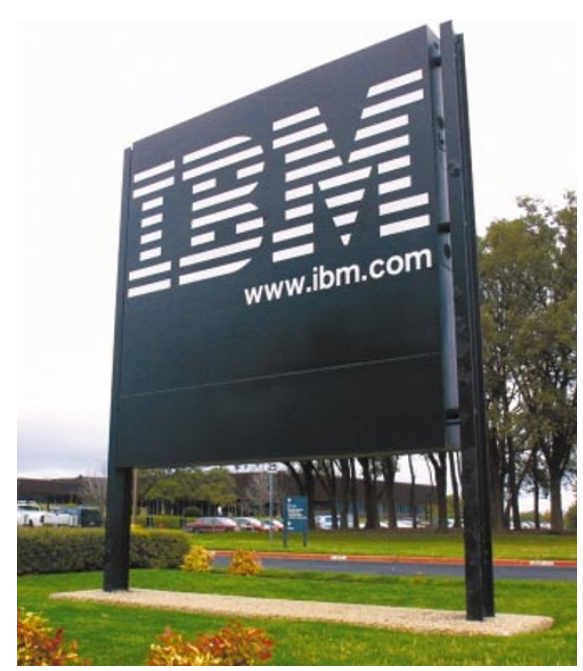

Different outlooks: R\&D at Marconi (far right) has been hit hard, but budgets look safer elsewhere.
At larger companies, the downturn may accelerate recent trends in commercial R\&D, which have seen firms demand that ideas are pushed much more quickly from research into marketable products. "There is a compression of timescales," says Luke Georghiou, director of PREST, the Policy Research in Engineering, Science and Technology group at the University of Manchester, who has just completed a study of how six of the largest high-tech companies manage R\&D.

This means that the biggest pressures will be felt by staff working in product development - which accounts for more than $90 \%$ of high-tech firms' R\&D. But another trend is affecting the bench scientists responsible for the ' $R$ ' part of this effort: a tendency to farm out basic research to academic groups or government research labs, rather than doing the work in-house.

\section{Pooling resources}

According to the latest edition of the Organisation for Economic Co-operation and Development's biannual report on science, technology and industry, published last month, industry now funds around 6\% of all research in government and highereducation establishments, up 50\% from the 1998 figure. "If the research really is basic and far from a product, we will seek expertise from universities or government labs," confirms Motorola's Roberson.

Lower revenues may also persuade firms to band together to fund basic research, says Paul Peercy, dean of the College of Engineering at the University of Wisconsin-Madison: "Firms are pooling resources and asking universities to look out for research that goes eight to ten years into the future." Peercy cites the example of the Semiconductor Research Corporation. Based in Durham, North Carolina, the corporation channels funds from chip makers, including Intel, Lucent and Motorola, into basic-research
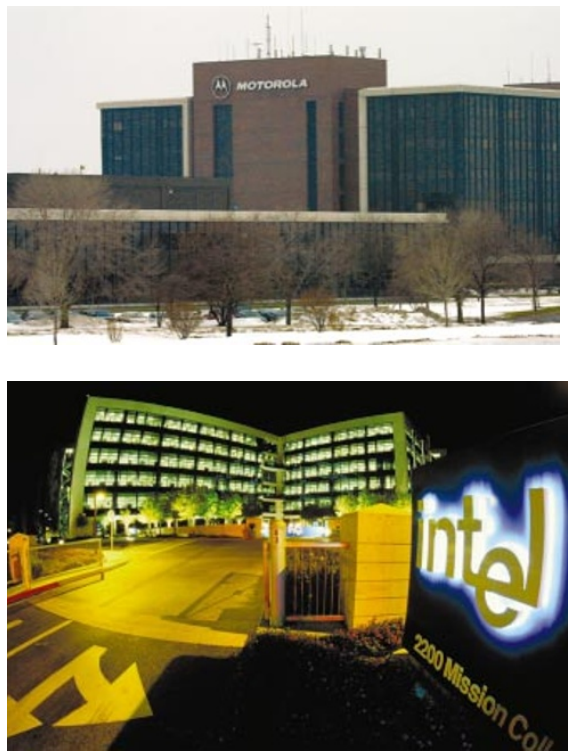

programmes in US universities. The organization says it will distribute around \$30 million this year.

Researchers left behind in the corporate labs have mixed views about the impact of these developments. "There have been big changes," says one researcher at Agere Systems, formerly the microelectronics division of Lucent. "Managers are not so patient, they want to see a product in the short term." But those at companies that have suffered less than Lucent and Agere are confident that inhouse fundamental research will still receive support. "We have been asked to think about spin-offs," says a scientist doing basic research with Btexact Technologies, the research arm of British Telecommunications. "But we are still able to tackle the same issues. Our work could have a big pay-off, so all telecommunications companies will have to have at least some people looking at this stuff."

Ultimately, the length of the downturn may determine how corporate $\mathrm{R} \& \mathrm{D}$ will fare. Financial forecasting, always an imprecise science, will be made doubly difficult by the global instability stemming from the terrible events of 11 September. Some executives, Motorola's Roberson among them, admit their plans could change if the climate does not improve within the next few years. Others, such as those at Intel, say they will protect $\mathrm{R} \& \mathrm{D}$ come what may. Commercial realities will inevitably intervene at some point, however, and few believe that R\&D budgets could be maintained at current levels through a deep and prolonged recession.

But with investors keeping an eye on $R \& D$ spending, and executives keen to keep the product pipeline flowing, R\&D budgets look safe for now. As Tom Theis, director of physical science research at IBM, says: "You're either investing for the future, or you're not."

Declan Butler is Nature's European corres pondent; Jim Giles is Nature's ass istant New $s$ and Features editor.

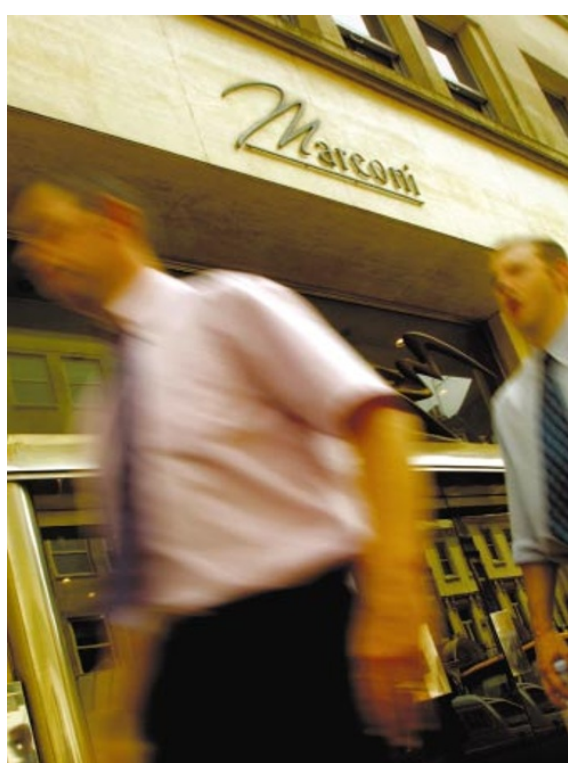

